\title{
RELATIONSHIP BETWEEN COPING STRATEGIES AND EMOTIONAL INTELLIGENCE AMONG PATIENTS WITH SCHIZOPHRENIA
}

\author{
Marina Perković Kovačević ${ }^{1,2}$, Ivan Požgain ${ }^{1,2}$, Pavo Filaković ${ }^{3}$ \& Ivana Grujčić ${ }^{1}$ \\ ${ }^{I}$ Department of Psychiatry, University Hospital Centre Osijek, Osijek, Croatia \\ ${ }^{2}$ Department of Psychiatry and Psychological Medicine, Josip Juraj Strossmayer University of Osijek, \\ Faculty of Medicine, Osijek, Croatia \\ ${ }^{3}$ Faculty of Dental Medicine and Health, Josip Juraj Strossmayer University of Osijek, Osijek, Croatia
}

received: 14.6.2018;

revised: 20.8.2018;

accepted: 5.9 .2018

\begin{abstract}
SUMMARY
Background: Behavioural investigation has become increasingly more focused on emotional intelligence as researchers strive to understand its influence on various social interactions. Recent research indicates that EI plays an integral role in adopting active and effective coping strategies. The aim of this study was to investigate the relationship between emotional intelligence and coping strategies in patients with schizophrenia.

Subjects and methods: The research included 102 stable patients with ICD-10 diagnosis of schizophrenia. The sample consisted of $46(45.1 \%)$ female and $56(54.9 \%)$ male patients, in the $18-55$ age range $(M=35.54 ; s d=10.48)$. All the participants completed the Questionnaire of Emotional Intelligence and Competence (UEK-45) and the Coping Inventory for Stressful Situations (CISS).

Results: Data were analysed using the correlation coefficient and linear regression analysis. The results showed that emotional intelligence correlates significantly with both task-oriented and avoidance-oriented strategies (including social diversion and distraction). Regression analysis revealed that emotional intelligence can be a significant predictor for these two coping strategies (task-oriented and avoidance-oriented strategies (including social diversion and distraction)).

Conclusion: Patients with lower emotional intelligence mainly use strategies focused on coping with their own emotions. These results may prompt the devising of prevention and treatment programs for patients suffering from schizophrenia. Namely, numerous studies and research on emotional intelligence show that emotional intelligence can be enhanced through learning and behaviour modification at any age.
\end{abstract}

Key words: emotional intelligence - coping strategies - schizophrenia

\section{INTRODUCTION}

Nowadays, the concept of coping with stress is broadly defined as a response to a stressful situation that helps re-establish psychosocial adjustment (McCrae \& Costa 1986).

Coping strategies pertain to certain behavioural patterns in stressful situations. Although they include many activities, most coping strategies reflect efforts to improve a troubled situation, such as making a plan or taking action (Mirnics et al. 2013). The model most commonly used in research of coping strategies is the Lazarus Transactional Model of Stress and Coping, which defines coping as constantly changing cognitive and behavioural patterns to manage specific external and/or internal demands regarded as consuming or exceeding one's resources (Lazarus \& Folkman 2004). In their research, Lazarus \& Folkman (1984) indicate two basic types of coping strategies: problem-focused coping strategies and emotion-focused coping strategies. The first type aims to solve the problem and is directly focused on the root cause of stress, and the second type includes cognitive regulation of emotional reactions in stressful situations, i.e. re-interpretation of a stressful event (Hobfoll 1988). Endler \& Parker (1990) believe that in addition to those two, there is also a third type of coping - avoidance. Kohlmann, Weidner \& Messina (1996) define it as diverting attention from the root cause of stress or absence of any reaction to the stressor.

In terms of its efficiency, coping with stress can be adaptive, helping a person to successfully cope with stressors and minimize any dangers. On the other side, it can be maladaptive and result in unnecessary additional difficulties for the person and their surroundings. Adaptive options contribute to the person's wellbeing - good health, productivity, satisfaction with life and personal growth (Schafer 1996). To successfully differentiate between adaptive and maladaptive coping strategies, it needs to be established whether a person's reactions are efficient in a given situation and whether such reactions are appropriate for that person. No reaction is good or bad in itself, which is why it must only be observed in a relevant context. Actively dealing with problems proved beneficial for relieving tension and relaxing, as well as for reducing the risk of illnesses. On the other side, denying the gravity of the situation and repressing one's emotions might seem helpful at first, but over time, it increasingly interferes with coping with stress, i.e. with adapting to a new situation (Pregrad 1996). 
Researching methods of coping with stressors is of particular interest for clinical psychology. Knowledge acquired in that area directly impacts the understanding and interpreting of different disorders, both as part of the psychodiagnostic process and as guidelines for selection of specific therapeutic techniques and interventions in providing psychological help.

Bar-On \& Parker (2000) refer to coping strategies and ability to adapt as the basic elements of emotional intelligence. According to Goleman, emotional intelligence includes" ...abilities such as being able to motivate oneself in the state of frustration; control one's impulses and delay gratification; control one's mood and being able to prevent stress from affecting one's thinking process; being capable of empathy and hope." (Matthews et al. 2002, Jakovljević \& Ostojić 2013). First operational construct of emotional intelligence was formulated by Mayer and Salovey in 1990, when they defined emotional intelligence as "the ability to monitor one's own and others' feelings and emotions and to use this information to guide one's thinking and actions" (Matthews et al. 2002, Gregl et al. 2014). The EI model consisted of: appraising emotions in oneself and others and expressing them; managing one's own emotions and those of others; and using emotions to adapt. However, since perceiving of emotions was not included in the definition, in 1997, the authors modified the model and defined emotional intelligence as the ability to perceive accurately, appraise and express emotion; the ability to access and/or generate feelings when they facilitate thought; the ability to understand emotion and emotional knowledge; and the ability to regulate emotions to promote emotional and intellectual growth (Gutierrez-Cobo et al. 2017).

There are several EI models that constitute the theoretical framework for conceptualization of the construct. Although different, the models are not contradictory, but rather take somewhat different perspective and view of emotional intelligence. Namely, emotional intelligence can be studied as a character trait (trait EI) and tested with questionnaires, or as ability (ability EI) and tested with tests (Petrides \& Furnham 2000). According to the authors (Petrides \& Furnham 2001), these two EI types represent two differing constructs and not just different methods of measuring the same construct. Emotional intelligence as a character trait comprises behavioural dispositions and perception and appraisal of one's own abilities. Although self-report instruments are criticised and often regarded as being too subjective, research shows them to be valid and have satisfactory psychometric characteristics (O'Connor \& Little 2003). Since Petrides' understanding of emotional intelligence as a character trait is most suited for our research question, we will analyse it in more detail hereinafter. Namely, Petrides and associates define emotional intelligence as a constellation of behavioural dispositions and self perceptions pertaining to one's own ability to perceive, process and utilize emotional information.
Therefore, their model conceptualizes EI as a character trait and includes four interrelated factors: wellbeing, self-control, emotionality and sociability, whereby the first one is related to one's perceived happiness in life, optimism about the future and appraisal of own self-esteem, while the other three are related to control and management of emotions. This attempt by Petrides to scientifically establish emotional intelligence as a set of self-perceptions and dispositions connected with emotions and emotional functioning proved to be fully concordant with the existing personality trait classification, because EI understood that way represents the reconceptualization of lower hierarchical level personality traits (Petrides et al. 2007). In accordance with the above, we can conclude that Petrides' understanding of emotional intelligence as a character trait paved the way for considering the prospects of improving EI (Schulze \& Roberts 2005). Ciarrochi also points out that EI can be enhanced only if we understand it as a character trait because a person's typical behaviour can be influenced much more effectively than their ability. Thus, the prevailing view nowadays is that emotional intelligence, unlike IQ, can be enhanced (Lantieri \& Goleman 2008).

The research interest in establishing the correlation between emotional intelligence and coping strategies stems from that understanding. A number of authors have determined that correlation between coping strategies and EI definitely exists, but most of the research has been conducted on a non-clinical sample (Lopes et al. 2004, Eskay 2011). In line with that, more recent research has confirmed a significant link between higher levels of emotional intelligence and more effective coping strategies, better social skills, better emotion management, faster recovery from negative emotional states, lower level of negative and higher level of positive emotions, more adequate health-related behaviour, as well as better assessment of one's own health. It has been observed that persons with higher emotional intelligence cope with stress more successfully because they manifest their emotional states more appropriately and control their mood more suitably. Such people tend to adopt a more active approach and are more open to seeking both professional and non-professional help in solving their problems (Austin et al. 2005, Zeinder et al. 2012).

Research findings pertaining to the population of patients with schizophrena are in line with those obtained on non-clinical samples (Aunjitsakul \& Pitanupong 2018, Maat et al. 2012), although the authors point out a large portion of still unexplained variance, which points to necessity of further and more in-depth research of different psychosocial variables as predictors of therapeutic outcomes in patients with schizophrena (Fett et al. 2011).

Given the importance of both EI and coping strategies for preservation of mental health and for better functionality, the aim of this research is to examine the correlation between the two on a clinical sample of patients diagnosed with schizophrenia in order to suitably plan and devise effective psychosocial interventions employed in the course of treatment. 


\section{SUBJECTS AND METHODS}

The research included 102 stable patients with the ICD-10 diagnosis of schizophrenia. The patients were recruited between July 2017 and July 2018 at the Department of Psychiatry, University Hospital Centre Osijek, Croatia. The sample consisted of $46(45.1 \%)$ female and $56(54.9 \%)$ male patients, in the $18-55$ age range $(\mathrm{M}=35.54 ; \mathrm{sd}=10.48)$. The patients showed no evidence of mental retardation (IQ lower then 70), organic brain diseases, severe somatic conditions, or drug/alcohol dependence. The study was officially approved by the local Ethical Committee of the institution in which the study was conducted. After the aims and procedures of the study were explained to them, the patients were asked to written informed consent to participate. From the initial sample, seven subjects were not included in the sample: three of them withdrew their written informed consent and four did not complete the tests (for objective reasons). The sample in the study was heterogeneous in terms of age, gender, education, employment, marital and socioeconomic status, duration of illness, number of hospitalizations and type of antipsychotic therapy.

Emotional Intelligence was assessed using the Questionnaire of Emotional Intelligence and Competence (UEK-45; Takšić 1998). The UEK-45 consists of 45 items measured in a 5-point Likert-type scale ranging from (1) "never" to (5) "always" and organized in three separate scales. The UEK-45 scales are as follows: Perceive and Understand Emotion Scale; Express and Label Emotion Scale and Manage and Regulate Emotion Scale. The Questionnaire is intended for assessing emotional intelligence and the process of recognizing one's own emotional states and emotional states of others for the purpose of more efficient problem solving and more adequate behaviour regulation. Application time is not limited.

The Coping Inventory for Stressful Situations (CISS; Endler \& Parker 1990, Sorić \& Proroković 2002) was used as a multidimensional assessment of coping. Respondents were asked to rate each of the 48 items on a five-point Likert-type rating scale ranging from (1) "not at all" to (5) "very much." Respondents were asked to indicate how much they engage in different types of activities when faced with a difficult, stressful or upsetting situation. The Inventory defines the three coping dimensions of the CISS (task-oriented strategies, emotion-oriented strategies and avoidance-oriented strategies). Avoidance-oriented scale also includes two subscales - distraction and social diversion.

Assessments were conducted by experienced clinical psychologists.

\section{Statistical Analysis}

Data was analysed using the Pearson product-moment correlations to determine associations between EI and coping. In addition, a linear regression analysis was conducted to calculate the proportion of variance in different coping domains accounted for by emotional intelligence variable. EI was entered as a predictor variable and CISS scales served as dependent variables. The level of significance was set at $\mathrm{P}$ of 0.05 . All the statistical analyses were performed using the SPSS version 19.0 (SPSS Inc., Chicago, IL, USA).

\section{RESULTS}

Data was initially analysed by using the Pearson's correlation coefficient. The results revealed that total emotional intelligence and all of its subscales significantly correlate with most of the subscales of coping strategies (except emotion-oriented strategies). The results obtained by using the Pearson's correlation coefficient are presented in Table 1.

Linear regression was used to find which emotional intelligence subscales provided the best predictive validity for subscales of coping strategies. Linear regression was conducted with emotional intelligence as an independent variable and all the subscales of coping strategies as dependent variables. The results obtained are presented in Table 2. Emotional intelligence accounted for $61 \%, 0 \%, 30 \%, 29 \%$ and $14 \%$ of the variance for task-oriented strategies, emotion-oriented strategies, avoidance coping, social diversion and distraction. However, emotional intelligence significantly predicted task-oriented strategies $(\beta=0.787)$, avoidance coping $(\beta=0.561)$, social diversion $(\beta=0.547)$ and distraction $(\beta=0.393)$.

Table 1. Intercorrelations between coping strategies and EI

\begin{tabular}{lccccccccc}
\hline Variable & EI & PUES & ELES & MRES & TOS & EOS & AOS & SD & D \\
\hline EI & 1 & $0.906^{* *}$ & $0.901^{* *}$ & $0.873^{* *}$ & $0.787^{* *}$ & 0.103 & $0.561^{* *}$ & $0.547^{* *}$ & $0.393^{* *}$ \\
PUES & & 1 & $0.743^{* *}$ & $0.676^{* *}$ & $0.652^{* *}$ & 0.103 & $0.392^{* *}$ & $0.429^{* *}$ & $0.241^{*}$ \\
ELES & & & 1 & $0.672^{* *}$ & $0.713^{* *}$ & 0.115 & $0.544^{* *}$ & $0.513^{* *}$ & $0.411^{* *}$ \\
MRES & & & & 1 & $0.749^{* *}$ & 0.056 & $0.574^{* *}$ & $0.529^{* *}$ & $0.408^{* *}$ \\
TOS & & & & & 1 & 0.123 & $0.644^{* *}$ & $0.628^{* *}$ & $0.448^{* *}$ \\
EOS & & & & & & 1 & $0.240^{*}$ & $0.203^{*}$ & $0.226^{*}$ \\
AOS & & & & & & 1 & $0.785^{* *}$ & $0.902^{* *}$ \\
SD & & & & & & & & 1 & $0.501^{* *}$ \\
D & & & & & & & & & 1 \\
\hline
\end{tabular}

Legend: EI - Emotional intelligence; PUES - Perceive and Understand Emotion Scale; ELES - Express and Label Emotion Scale; MRES - Manage and Regulate Emotion Scale; TOS - Task-oriented strategies; EOS - Emotion-oriented strategies; AOS - Avoidance -oriented strategies; SD - Social diversion; D - Distraction 
Table 2. Results of linear regression pertaining to predicting coping strategies based on EI

\begin{tabular}{lcccccc}
\hline Variables & $\mathrm{R}$ & adjusted R & Sig. F Change & Stand.Beta & t-test & $\mathrm{P}$ \\
\hline TOS & 0.787 & 0.616 & 0.000 & 0.787 & 12.755 & 0.000 \\
EOS & 0.103 & 0.001 & 0.305 & 0.103 & 1.032 & 0.305 \\
AOS & 0.561 & 0.308 & 0.000 & 0.561 & 6.779 & 0.000 \\
SD & 0.547 & 0.293 & 0.000 & 0.547 & 6.540 & 0.000 \\
D & 0.393 & 0.146 & 0.000 & 0.393 & 4.276 & 0.000 \\
\hline
\end{tabular}

\section{DISCUSSION}

To our knowledge, this is the first study to find that emotional intelligence and its scales are associated with coping strategies in schizophrenia. In general, findings of the present study showed that total emotional intelligence and its scales have a significant positive relationship with task-oriented strategies, avoidanceoriented strategies and two subscales of avoidanceoriented scale - distraction and social diversion. Only emotion-oriented strategies had no significant correlation with emotional intelligence and its subscales.

There are numerous studies studying the correlation between coping strategies and emotional intelligence (Bibi et al. 2015, Erözkan 2013, Kim \& Han 2015, Larijani et al. 2017, Moradi et al. 2011, Noorbakhsh et al. 2010, Ramos et al. 2007, Saklofske et al. 2007, Sharma \& Kumar 2016, Sunil 2009), and they reported various results depending on the definitions, classification principles of coping and use of different instruments (Erözkan 2013). Nevertheless, there is a general opinion that high emotional intelligence leads to using active, positive, problem-oriented and effective coping strategies rather than passive, emotionfocused and negative strategies (Erözkan 2013). The present study partially confirms this tendency.

Positive relationship of emotional intelligence and its scales with task-oriented strategies is consistent with findings of several studies conducted on a nonclinical sample (Larijani et al. 2017, Moradi et al. 2011, Kim \& Han 2015). Task-oriented strategies are described as purposeful, task-oriented efforts aimed at solving or cognitively restructuring the problem, or as attempts to alter the situation. Their main emphasis is on the task or planning, and on attempts to solve the problem (Endler \& Parker 1999). Kim \& Han (2015) reveal that people who perceive their emotions clearly engage in problem-focused, active coping. They assert that those who are aware of their emotions have the necessary information about their objectives and therefore have the ability to make sound decisions to solve their problem. In addition, they suggest that people who perceive not only their emotions, but also those of others clearly, have a wealth of information, which helps them employ their resources swiftly to minimize any adverse impacts of the problem.

However, the above-mentioned studies also found a negative correlation between emotional intelligence and avoidance strategies, which is not the case in the present study. The findings of the present study are partially supported by those of Mohammadi et al. (2008) who reported a positive relationship between EI and each of the three investigated coping strategies (efficient, non-efficient and refer-to-others). Mohammadi et al. (2008) showed that students with higher emotional intelligence use both effective and non-effective coping strategies while encountering stressful situations, though they use the effective ones more frequently than the non-effective.

This finding differs significantly from the results of previous studies, but we have to consider the fact that all previous research was conducted on non-clinical population. Numerous research on patients suffering from schizophrenia established avoidance as the dominant coping strategy, which is different from dominant coping strategies of healthy adult individuals (Jansen et al. 1999, Ponizovsky et al. 2013). The authors maintain that choosing a suitable coping strategy is of utmost importance because a strategy not suited to the situation only exacerbates stress symptoms (Gross \& Levenson 1997). Patients suffering from schizophrenia depend on the help of others to a much greater extent than healthy individuals; they are generally less independent and functional in their everyday lives and it is much more likely that certain complex problems they face will be solved by someone else in their surroundings while they avoid them, which, for them, will not necessarily result in aggravated stress symptoms. From that standpoint, the finding is not so surprising and it is no wonder that EI of patients with schizophrenia positively correlates with avoidance strategy. Another possible explanation for development of coping strategies is the influence of factors other than EI. Considering the clinical features of schizophrenia and the fact that its peak incidence occurs at a working age, when the person engages in a wide range of work, social and family activities, factors which could influence the coping strategies are: demographic characteristics (age, sex, level of education, employment status, marital status, income level, social and family relationships), clinical factors (duration of illness, number of hospitalizations, dominance of positive or negative symptoms), personality factors (self-confidence, self-efficacy, extroversion/introversion, etc.) and characteristics of stressful situations (type, intensity and predictability of the situation). Therefore, in evaluating the implementation of coping strategies, we should consider the interrelations of many other factors. However, in the present study, we investigated just one effective variable - emotional intelligence and its 
relationship with coping strategies. There may also be intervening and moderator variables that influence the correlation between emotional intelligence and coping strategies. Therefore, in future studies, other factors besides emotional intelligence should also be investigated or controlled.

\section{Limitations of the study}

This study should be evaluated with certain important limitations in mind. For example, the sample size is relatively small, due to which the findings of the study may not be generalizable. Data were collected only in one hospital, which also may limit the generalizability of the present results. We also cannot ignore the potential impact of other factors which were not investigated in this study.

\section{CONCLUSION}

This study examined the relationship between emotional intelligence and coping strategies among patients with schizophrenia. Through analysis, it was concluded that patients with schizophrenia with higher emotional intelligence used both task-oriented and avoidanceoriented coping strategies, including social diversion and distraction. The results confirm that patients with high emotional intelligence are more flexible in coping with stressors and choose different strategies. Patients with lower emotional intelligence mainly use strategies focused on coping with their own emotions. Since the World Health Organization (WHO 2005) encourages the development of effective treatment programs for patients with mental disorders (Štrkalj-Ivezić et al. 2013), these results may prompt the devising of prevention and treatment programs for patients suffering from schizophrenia.

Namely, numerous studies and research on emotional intelligence show that emotional intelligence can be enhanced through learning and behaviour modification at any age (Sharma \& Kumar 2016).

\section{Acknowledgements: None.}

Conflict of interest: None to declare.

\section{Contribution of individual authors:}

Marina Perković Kovačević: Study conception and design; planning and designing data acquisition, conducting data acquisition process, analysis and interpretation of data; drafting of manuscript;

Ivan Požgain: planning and designing data acquisition, drafting of manuscript; critical revision;

Pavo Filaković: planning and designing of the data acquisition, critical revision;

Ivana Grujčić: planning and designing data acquisition, conducting data acquisition process.

\section{References}

1. Aunjitsakul W \& Pitanupong J: Schizophrenias' Quality of Life and Emotional Intelligence in Songklanagarind Hospital. Songkla Med J 2018; 36:61-71

2. Austin EJ, Saklofske DH, Huang SHS \& McKenney D: Measurement of trait emotional intelligence: testine and cross validating a modified version of Schutte et al.'s (1998) measure. In: Noorbakhsh SN, Besharat MA \& Zarei J: Emotional intelligence and coping styles with stress. Procedia-Social and Behavioural Sciences 2010; 5:818-822

3. Bar On $R$ \& Parker JDA: The handbook of emotion intelligence. San Francesco: Jossy-Bass Books, 2000

4. Bibi F, Kazmi SF, Chaudhry AG \& Khan SE: Relationship between emotional intelligence and coping strategies among university teachers of Khyber Pakhtunkhwa. Pakistan Journal of Science 2015; 67:81-84

5. Endler NS \& Parker JDA: Multidimensional assessment of coping. A critical evaluation. Journal of Personality and Social Psychology 1990; 58:544-854

6. Erözkan A: Exploring the relationship between perceived emotional intelligence and coping skills of undergraduate students. International Journal of Human Sciences 2013; 10:1537-1549

7. Eskay M: Harmonizing educational differences from an international perspective. In: Moradi A, Pishva N, Ehsan HB, Hadadi P \& Pouladi F: The relationship between coping strategies and emotional intelligence, ProcediaSocial and Behavioural Sciences 2011; 30:748-751

8. Fett AK, Viechtbauer W, Dominguez MD, Penn DL, van Os $J$ \& Krabbendam L: The relationship between neurocognition and social cognition with functional outcomes in schizophrenia: a meta-analysis. Neuroscience anf Biobehavioral Reviews 2011; 35:573-88

9. Gregl A, Kirigin, $M$, Sućeska Ligutić $R \&$ Bilać $S$ : Emotional competence of mothers and psychopathology in preschool children with specific language impairment (SLI). Psychiatria Danubina 2014; 3:261-270

10. Gross JJ \& Levenson RW: Hiding feelings: The acute effects of inhibiting negative and positive emotion. Journal of Abnormal Psychology 1997; 106: 95-103

11. Gutierrez-Cobo MJ, Cabello R \& Fernandez-Berrocal P: The Three Models of Emotional Intelligence and Performance in a Hot and Cool go/no-go Task in Undergraduate Students. Frontiers in behavioral neuroscience 2017; 11:3

12. Hobfoll SE: The ecology of stress. New York: Hemisphere Publishing Corp, 1998

13. Jakovljević M \& Ostojić Lj: Professionalism in contemporary medicine: if it is an important academic issue, then surely it is a 'hot' issue as well. Medicina Academica Mostariensia 2013; 1:6-17

14. Jansen LM, Gispen-de Wied CC \& Kahn RS: Coping with stress in schizophrenia. Schizophrenia Research 1999; 36:186

15. Kim MR \& Han SJ: A study of Emotional Intelligence and Coping Strategies in Baccalaureate Nursing Students. International Journal of Bio-Science and Bio-Technology 2015; 7:275-282

16. Kohlmann CW, Weidner $G$ \& Messina CR: Avoidant coping style and verbal-cardiovascular response dissociation. Psychology and Health 1996; 11:371-384

17. Lackovic-Grgin K: Stress in Children and Adolescents. Jastrebarsko: Naklada Slap, 2000 
18. Lantieri L \& Goleman D: Exercises for Development of Emotional Intelligence. Split: Harfa, 2008

19. Larijani TT, Movaghari MR, Rostami M, Zamani $N$ \& Ghadirian F: The Relationship between Emotional Intelligence and Coping Styles Against Stress Among Nurses. World Journal of Research and Review 2017; 4:71-75

20. Lazarus RS \& Folkman S: Stress, Assessment and Coping. Jastrebarsko: Naklada Slap, 2004

21. Lazarus RS \& Folkman S: Stress, Appraisal and Coping. New York: Springer, 1984

22. Lopes PN, Bracket M A, Nezlek J B, Schutz A, Sellin I \& Salovey P: Emotional intelligence and social interaction. Personality \& Social Psychology Bulletin 2004; 30:10181034

23. Maat A, Fett AK \& Derks EM: Social cognition and quality of life in schizophrenia. Schizophrenia Research 2012; 137:212-8

24. Matthews $G$, Zeidner $M$ \& Roberts RD: Emotional Intelligence: Science and Myth. Cambridge and London: The MIT Press and A Bradford Book, 2002

25. McCrae RR. \& Costa PT Jr: Personality, coping and coping effectiveness in an adult sample. Journal of Personality 1986; 54:385-405

26. Mirnics Z, Heincz O, Bagdy G, Surányi Z, Gonda X, Benko A, Molnar E, Jakšić N, Lazary J \& Juhasz G: The relationship between the big five personality dimensions and acute psychopathology: mediating and moderating effects of coping strategies. Psychiatr Danub 2013; 4:379388

27. Mohammadi CD, Torabi $C A \&$ Ghorabi B: The relation between coping styles and emotional intelligence of students. In: Moradi A, Pishva N, Ehsan HB, Hadadi P \& Pouladi F: The relationship between coping strategies and emotional intelligence. Procedia-Social and Behavioural Sciences 2011; 30:748-751

28. Moradi A, Pishva N, Ehsan HB, Hadadi P \& Pouladi F: The relationship between coping strategies and emotional intelligence. Procedia-Social and Behavioural Sciences 2011; 30:748-751

29. Noorbakhsh SN, Besharat MA \& Zarei J: Emotional intelligence and coping styles with stress. Procedia-Social and Behavioural Sciences 2010; 5:818-822

30. O'Conner RM \& Little I: Revisiting the predictive validity of emotional intelligence: Selfreport versus ability-based measures. In: Mohorić T, Takšić V \& Avsec A: Emotional competence and the Big Five. Prevencija - (re)habilitacija - psihoedukacija - kroz interdisciplinarnost. Jastrebarsko: Naklada Slap, 2007
31. Petrides $K V \&$ Furnham A: On the dimensional structure of emotional intelligence. Pers Individ Dif 2000; 29:313320

32. Petrides KV, Furnham A \& Frederickson N: Emotional intelligence - Argue for a trait approach to the misunderstood construct. The Psychologist 2004; 17:67-74

33. Petrides KV, Perez-Gonzalez JC \& Furnham A: On the criterion and incremental validity of trait emotional intelligence. Cogn Emot 2007; 21: 26-55

34. Ponizovsky AM, Finkelstein I, Poliakova I, Mostovoy D, Goldberger $N$ \& Rosca P: Interpersonal distances, coping strategies and psychopathology in patients with depression and schizophrenia. World Journal of Psychiatry 2013; 22:74-84

35. Pregrad J: Stress, Trauma, Recovery: A textbook of the 'psycho-traumatic trauma and recovery basics'. Zagreb: Društvo za psihološku pomoć, 1996

36. Ramos N, Fernandez-Berrocal P \& Extrema N: Perceived emotional intelligence facilitates cognitive emotional processes of adaptation to an acute stressor. Cognition and Emotion 2007; 21:758-772

37. Saklofske DH, Austin EJ, Galloway J \& Davidson K: Individual difference correlates of health-related behaviours: preliminary evidence for links between emotional intelligence and coping. Personality and Individual Differences 2007; 42:491-502

38. Schafer W: Stress management for wellness. Fort Worth: Harcourt Brace College Publishers, 1996

39. Schulze $R$ \& Roberts RD: Emotional intelligence: An international handbook. Ashland. OH: Hogrefe \& Huber Publishers, 2005

40. Sharma $R$ \& Kumar P: Emotional Intelligence and Stress Coping Styles: A Study of Doctors of Private Hospitals in and Around Chandigarh. International Journal of Management \& Social Sciences 2016; 3:660-675

41. Sorić I \& Proroković A: Coping Inventory for Stressful Situations by Endler and Parker (CISS). In: Proroković A, Lacković Grgin K, Ćubela Adorić V \& Penezić, Z (ur.): Zbirka psihologijskih skala i upitnika. Zadar: Sveučilište u Zadru 2002; 147-151

42. Sunil $K \&$ Rooprai KY: Role of Emotional Intelligence in Managing Stress and Anxiety at workplace. Proceedings of ASBBS 2009; 16:1

43. Štrkalj-Ivezić S, Vrdoljak M, Mužinić L \& Agius M: The impact of a rehabilitation day centre program for persons suffering from schizophrenia on quality of life, social functioning and self-esteem. Psychiatr Danub 2013; 2:194-199

Correspondence:

Marina Perković Kovačević, MA

Department of Psychiatry, University Hospital Centre Osijek

Josipa Huttlera 4, 31000 Osijek, Croatia

E-mail:marina.perkovic@gmail.com 